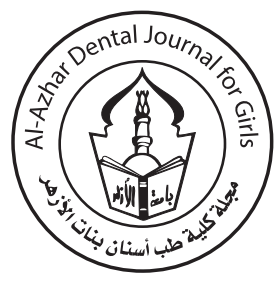

\title{
The Effect of Occlusion and Two Denture Base Material on Muscle Activity and Masticatory Efficiency of Complete Dentures
}

\author{
Marwa Ezz El-Din ${ }^{1}$, Mohammed Essam El-Din Sanad ${ }^{2}$, Hala M. Gamal El-Din ${ }^{3}$
}

Codex : 27/1904

azhardentj@azhar.edu.eg

http://adjg.journals.ekb.eg

DOI: $10.21608 /$ adjg.2019.5985.1038

\section{KEYWORDS}

Conventional, flexible, occlusion,

Electromyography, adjustments.

\begin{abstract}
Purpose: The aim of this study was to evaluate the effect of occlusion and two different denture base material on muscle activity and masticatory efficiency of complete dentures. Material and Methods: Two complete dentures of different material, conventional and flexible denture base material with different occlusal schemes, starting with unbalanced occlusion and converted into bilateral balanced occlusion through three different ways of remounting, laboratory, clinical and intra-oral selective grinding applied on three different posterior teeth assemblies were delivered to patients who were totally edentulous (all were men range age 50-60 years). Muscle activity and masticatory efficiency were evaluated with two different type of food, carrots resembling hard food and banana resembling soft food. The occlusal schemes were switched on the patients' denture bases. Two-way repeated-measures ANOVA and test were used to examine the alterations between the occlusal schemes, denture base materials and chewing strokes and their relations. Results: No significant difference was found in electromyographic activity or masticatory efficiency between the occlusal schemes and denture base materials with soft food $(\mathrm{p}<0.05)$. A significant difference was found in electromyographic activity and masticatory efficiency with bilateral balanced occlusion obtained through clinical remounting with flexible denture base material with hard food. Conclusions: Within the limitation of this study, it was concluded that complete dentures with bilateral balanced occlusion obtained through clinical remounting found significant differences in muscle activity and masticatory efficiency with hard food. Flexible dentures are better than conventional dentures in muscle activity and masticatory efficiency.
\end{abstract}

- Paper extracted from $\mathrm{PhD}$ thesis titled "The effect of occlusion and two denture base material on muscle activity and masticatory efficiency of complete dentures.

1. M.D.Sc, in Removable Prosthodontics, Private Dentist.

2. Professor of Removable Prosthodontics Department, Faculty of Dental Medicine for Girls, Al-Azhar University.

3. Professor of Removable Prosthodontics Department, Faculty of Dental Medicine for Girls, Al-Azhar University. 


\section{INTRODUCTION}

The World Health Organization (WHO) describes health as "a state of complete physical, mental and social well-being, not merely the absence of disease or infirmity". This current approaching to wellness lends itself to oral health as well. Damage of teeth is a difficult situation, even worse when the patient is completely edentulous ${ }^{(1)}$.

When replacing natural teeth with artificial teeth, it is imperative that the replacement functions are in harmony with entire system of jaws, muscles and joints. One of the most important determinants of these inevitable denture movements is the way the teeth come together. Certain dentists believe there should be cusps on the teeth and they must be in complete accord with the lively of temporomandibular joint function. Few consider that the teeth should be cuspless. There are numerous concepts, techniques, and philosophies concerning complete denture occlusion ${ }^{(2)}$.

Occlusal concepts which are balanced and unbalanced occlusion and their resultant roles are of worry to the dentist so that loss of residual tissues of the mouth, which may be attributed to the malocclusion can be reduced. Search for ideal denture occlusion which provides full stability and masticatory efficiency without compromising the health of the underlying bone is required ${ }^{(3)}$.

Electromyographic activity evaluation is an objective method that provides the masticatory muscle behavior in many situations during the function. EMG technique is based on capturing electric potentials from the muscles in action during natural and voluntary movements. Alterations in occlusal relation due to residual ridge reabsorption and complete denture seating would affect the EMG activity of masticatory muscles ${ }^{(4)}$.

For long polymethyl methacrylate has led the field of denture base materials but today flexible dentures has arisen as a major contestant to polymethyl methacrylate dentures. Flexible dentures are considered perfect substitutes to conventional and partial acrylic dentures. The criteria of better masticatory performance and masticatory efficiency of dentures may alter the future potential of denture base materials ${ }^{(5)}$.

\section{MATERIAL AND METHODS}

\section{Patients Selection}

Completely edentulous patients were selected from the Outpatients' Clinics and Laboratories, Department of Removable Prosthodontics, Faculty of Dental Medicine for Girls, Al-Azhar University.

The patients were then divided into three equal groups. Each patient received two complete dentures. One was prepared of conventional acrylic resin and the other one was made of flexible acryl.

\section{Patients grouping:}

Group I: Bilateral balanced occlusion through laboratory remounting.

Group II: Bilateral balanced occlusion through clinical remounting.

Group III: Bilateral balanced occlusion through Intra oral selective grinding.

\section{Procedures:}

Construction of dentures and setting-up of the teeth with unbalanced occlusion for all groups were made in conventional way which were not subjected to any selective grinding.

Occlusal index for maxillary teeth using plaster.Face-bow record was obtained; this record was transferred to a semi-adjustable articulator.Both protrusive and lateral records were obtained and Lateral condylar guidance of both sides was obtained from Hanau equation: $\quad \mathrm{L}=\mathrm{H} / 8+12$

\section{Construction of posterior teeth assemblies:}

Maxillary and mandibular anterior teeth were left on trial denture bases, while maxillary and 
mandibular posterior teeth were removed.The modified maxillary and mandibular trial dentures were processed and polished.

The maxillary anatomical posterior teeth were set in their particular places in the maxillary occlusal index and luted with wax. After the maxillary posterior teeth were finished, the index was removed and lower cast was mounted on articulator and the posterior mandibular teeth were arranged according to posterior maxillary teeth (fig.1).

* All the steps were repeated for the flexible denture.

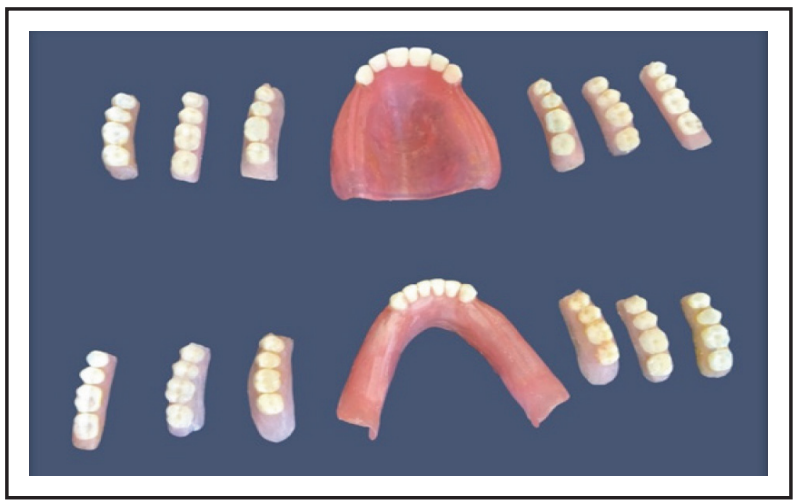

Figure (1): posterior teeth assemblies

\section{Denture delivery:}

Two dentures were ready for delivery, the conventional denture was given for one month to the patient first for adaptation followed by flexible one.

\section{Experimental steps:}

- Steps of balanced occlusion for the three groups:

\section{Group I: Bilateral balanced occlusion through laboratory remounting for conventional and flexible dentures:}

Laboratory remounting was done before removing the processed dentures from the master cast. After centric relation was completed, loosening of the condylar element of the articulator was carried out to allow smooth lateral and protrusive movements without interference.

Articulating paper with double color was used, for working and balancing side. Articulating paper was placed on each side respectively and any heavy contacts were adjusted. During movement, the incisal pin was always touching incisal table and pin was moved half way of incisal table of each side.

\section{Group II: Bilateral balanced occlusion through clinical remounting for conventional and flexible dentures:}

Clinical remounting was done by having some records from the patient mouth and corrections were applied on the articulator. Remounting: maxillary denture was done by using the remount index and plaster cast was poured.

Centric relation record was gained by using softened compound impression material and the patient was directed to close in centric relation until the teeth just touch each other so that any discrepancies in occlusion can be easily detected.

Remounting mandibular denture by placing the mandibular denture over the maxillary denture and the cast was mounted with plaster. Protrusive and lateral records were obtained from the patient as mentioned before.

For working side: grinding was from buccal cusps and its inclination. For balancing side: grinding was done in occlusal inclines in upper palatal to avoid losing vertical dimension.

\section{Group III: Bilateral balanced occlusion through Intra oral selective grinding for conventional and flexible dentures:}

Selective grinding was done using articulating paper. For centric correction, the patient was asked to open and close on the articulating paper to detect any premature contact. For protrusive and lateral corrections: the patient was asked to protrude and moves his mandible from side to side and any marks should be removed. 


\section{Experimental measurements:}

After one month, adaptation period, both Muscle activity and Masticatory efficiency were tested:

\section{A. Electromyographic activity test:}

Electromyography was used to record muscle activity of masseter and anterior temporalis muscles. While retaining the electrodes, the patients were asked to hold their jaws tightly. For Masseter muscle electrodes were placed one centimeter behind the palpated anterior border in the area of the greatest lateral expansion and the other electrode was placed caudal to the first one.

For anterior temporalis muscle electrodes were placed over its anterior portion at the area of its greatest lateral distension and the other electrode was placed relative to the first one. The ground electrode was placed on patient's forehead.

The records were gained while the patient was chewing standardized pieces of food: banana which represented soft food and carrot which represented hard food. The EMG signals were filtered, amplified and converted to digital signals at a sampling rate and printed.

\section{B. Masticatory efficiency test}

Masticatory efficiency was evaluated through three measures recorded while the patient was chewing standardized pieces of food: banana which represented soft food and carrot which represented hard food.

The records were obtained by counting the number of masticatory strokes required to reduce food to a certain particle size until swallowing. The time in seconds was measured from the first stroke until swallowing.

The conventional acrylic denture was taken from the patient and replaced with the flexible one and after one week adaptation period, the same measurements were performed.

\section{STATISTICAL ANALYSIS}

Values were presented as mean and standard deviation (SD) values. The results of KolmogorovSmirnov test indicated that most of the data were normally distributed (parametric data), therefore, one way analysis of variance (ANOVA) test was used to compare between different occlusions. This was followed by Tukey's post hoc test when the difference was found to be significant. Unpaired t test was used to compare both groups. The significance level was fixed at $p<0.05$. Statistical analysis was performed with SPSS 18.0 (Statistical Package for Scientific Studies, SPSS, Inc., Chicago, IL, USA) for Windows.

\section{RESULTS}

Patients were recalled after one month of wearing dentures with different occlusal assemblies and masticatory efficiency and electromyographic activity tests were performed.

\section{Electromyographic activity (EMG)}

\section{a. Masseter muscle (Soft food)}

In unbalanced occlusion a higher mean value was recorded in acrylic denture base, with no significant difference $(\mathrm{p}=0.815)$. In group $\mathrm{I}$, a higher mean value was recorded in acrylic denture base, with a significant difference $(\mathrm{p}=0.037)$. In group II and group III, a higher mean value was recorded in acrylic denture base, with no significant difference ( $\mathrm{p}=0.416 ; 0.441$ in group II and III respectively).

\section{b. Masseter muscle (hard food)}

In unbalanced occlusion a higher mean value was recorded in acrylic denture base, with no significant difference $(\mathrm{p}=0.0527)$. In group I, a higher mean value was recorded in acrylic denture base, with no significant difference $(\mathrm{p}=0.22)$. In group II and group III, a higher mean value was recorded in acrylic denture base, with no significant difference ( $\mathrm{p}=0.492 ; 0.582$ in group II and III respectively) (Table 1). 
Table (1): Comparison of EMG between acrylic denture base and flexible denture base (Masseter musclehard food) in different occlusions using t test

\begin{tabular}{|c|c|c|c|c|c|}
\hline $\begin{array}{c}\text { Masseter } \\
\text { Hard food }\end{array}$ & Unbalanced & $\begin{array}{c}\text { GP I } \\
\text { Laboratory } \\
\text { remounting }\end{array}$ & $\begin{array}{c}\text { GP II } \\
\text { Clinical } \\
\text { remounting }\end{array}$ & $\begin{array}{c}\text { GP III } \\
\text { Intra-oral } \\
\text { selective grinding }\end{array}$ \\
\hline \multirow{2}{*}{$\begin{array}{c}\text { Acrylic base } \\
\text { denture }\end{array}$} & Mean & 488.94 & 438.50 & 397.56 & 462.72 \\
\cline { 2 - 6 } & SD & 51.63 & 52.44 & 67.18 & 61.70 \\
\hline \multirow{2}{*}{ Flexible denture } & Mean & 455.49 & 415.08 & 383.53 & 450.46 \\
\cline { 2 - 6 } & SD & 41.66 & 53.40 & 44.62 & 62.86 \\
\hline
\end{tabular}

Significance level $p<0.05$

\section{Temporalis muscle (Soft food)}

In unbalanced occlusion a higher mean value was recorded in acrylic denture base, with no significant difference $(\mathrm{p}=0.89)$. In group $\mathrm{I}$, a higher mean value was recorded in acrylic denture base, with no significant difference $(\mathrm{p}=0.527)$. In group II and group III, a higher mean value was recorded in acrylic denture base, with no significant difference $(p=0.468 ; 0.603$ in group II and III respectively).

\section{Temporalis muscle (hard food)}

In unbalanced occlusion a higher mean value was recorded in acrylic denture base, with no significant difference $(\mathrm{p}=0.342)$. In group I, a higher mean value was recorded in acrylic denture base, with no significant difference $(\mathrm{p}=0.875)$. In group II and group III, a higher mean value was recorded in acrylic denture base, with no significant difference ( $\mathrm{p}=0.086 ; 0.068$ in group II and III respectively) (Table 2).

Table (2): Comparison of EMG between acrylic denture base and flexible denture base (Temporalis muscle-hard food) in different occlusions using t test

\begin{tabular}{|c|c|c|c|c|c|}
\hline $\begin{array}{c}\text { Temporalis } \\
\text { Hard food }\end{array}$ & Unbalanced & $\begin{array}{c}\text { GP I } \\
\text { Laboratory } \\
\text { remounting }\end{array}$ & $\begin{array}{c}\text { GP II } \\
\text { Clinical } \\
\text { remounting }\end{array}$ & $\begin{array}{c}\text { GP III } \\
\text { Intra-oral } \\
\text { selective grinding }\end{array}$ \\
\hline \multirow{2}{*}{$\begin{array}{c}\text { Acrylic base } \\
\text { denture }\end{array}$} & Mean & 352.71 & 315.05 & 305.90 & 333.94 \\
\cline { 2 - 6 } & SD & 36.45 & 39.82 & 25.69 & 23.68 \\
\hline \multirow{2}{*}{$\begin{array}{c}\text { Flexible } \\
\text { Denture }\end{array}$} & Mean & 339.79 & 311.39 & 293.47 & 318.72 \\
\cline { 2 - 6 } & SD & 31.77 & 36.59 & 30.89 & 21.62 \\
\hline
\end{tabular}

Significance level $p<0.05$ 


\section{Masticatory efficiency}

\section{Number}

\section{a. Masticatory efficiency-Number (soft food)}

In unbalanced occlusion a higher mean value was recorded in acrylic denture base, with a significant difference $(\mathrm{p}=0.0138)$. In group $\mathrm{I}$, a higher mean value was recorded in acrylic denture base, with a significant difference $(\mathrm{p}=0.0015)$. In group II and group III, a higher mean value was recorded in acrylic denture base, with a significant difference $(\mathrm{p}=0.00 ; 0.0013$ in group II and III respectively).

\section{b. Masticatory efficiency-Number (hard food)}

In unbalanced occlusion a higher mean value was recorded in acrylic denture base, with a significant difference $(\mathrm{p}=0.00)$. In group I, a higher mean value was recorded in acrylic denture base, with a significant difference $(\mathrm{p}=0.0029)$. In group II and group III, a higher mean value was recorded in acrylic denture base, with a significant difference $(\mathrm{p}=0.0005 ; 0.0002$ in group II and III respectively) (Table 3).

\section{Time (seconds)}

\section{a. Masticatory efficiency-Time (soft food)}

In unbalanced occlusion a higher mean value was recorded in acrylic denture base, with a significant difference $(\mathrm{p}=0.00)$. In group $\mathrm{I}$, a higher mean value was recorded in acrylic denture base, with a significant difference $(\mathrm{p}=0.0017)$. In group II and group III, a higher mean value was recorded in acrylic denture base, with a significant difference ( $\mathrm{p}=0.0002 ; 0.00$ in group II and III respectively).

\section{b. Masticatory efficiency-Time (hard food)}

In unbalanced occlusion a higher mean value was recorded in acrylic denture base, with no significant difference $(\mathrm{p}=0.073)$. In group I and group II a higher mean value was recorded in acrylic denture base, with a significant difference $(\mathrm{p}=0.0007$, $\mathrm{p}=0.001$ in group I and II respectively). In Group III, a higher mean value was recorded in acrylic denture base, with no significant difference $(\mathrm{p}=0.0663)$ (Table 4).

Table (3): Comparison of masticatory efficiency-Number (hard food) between acrylic denture base and flexible denture base in different occlusions using t test

\begin{tabular}{|c|c|c|c|c|c|}
\hline $\begin{array}{c}\text { Number } \\
\text { Hard food }\end{array}$ & Unbalanced & $\begin{array}{c}\text { GP I } \\
\text { Laboratory } \\
\text { remounting }\end{array}$ & $\begin{array}{c}\text { GP II } \\
\text { Clinical } \\
\text { remounting }\end{array}$ & $\begin{array}{c}\text { GP III } \\
\text { Intra-oral } \\
\text { selective grinding }\end{array}$ \\
\hline \multirow{2}{*}{$\begin{array}{c}\text { Acrylic base } \\
\text { denture }\end{array}$} & Mean & 21.83 & 18.17 & 18.15 & 20.00 \\
\cline { 2 - 6 } & SD & 2.40 & 2.23 & 3.37 & 2.61 \\
\hline \multirow{2}{*}{ Flexible denture } & Mean & 18.33 & 15.50 & 14.33 & 16.50 \\
\cline { 2 - 6 } & SD & 1.63 & 2.43 & 2.07 & 2.07 \\
\hline
\end{tabular}

Significance level $p<0.05$

Table (4): Comparison of masticatory efficiency-Time (hard food) between acrylic denture base and flexible denture base in different occlusions using t test

\begin{tabular}{|c|c|c|c|c|c|}
\hline $\begin{array}{c}\text { Time } \\
\text { Hard food }\end{array}$ & Mean & $\begin{array}{c}\text { Unbalanced } \\
\text { occlusion }\end{array}$ & $\begin{array}{c}\text { GP I } \\
\text { Laboratory } \\
\text { remounting }\end{array}$ & $\begin{array}{c}\text { GP II } \\
\text { Clinical } \\
\text { remounting }\end{array}$ & $\begin{array}{c}\text { GP III } \\
\text { Intra-oral } \\
\text { selective grinding }\end{array}$ \\
\hline $\begin{array}{c}\text { Acrylic base } \\
\text { denture }\end{array}$ & SD & 24.67 & 21.33 & 20.17 & 22.00 \\
\cline { 2 - 6 } Flexible denture & Mean & 23.17 & 2.58 & 3.19 & 2.76 \\
\cline { 2 - 6 } & SD & 1.47 & 1.50 & 16.33 & 20.33 \\
\hline
\end{tabular}




\section{DISCUSSION}

Medium body impression provides excellent replication of all anatomic structures. It has excellent tear strength and flexibility, which is essential when the impression is removed from undercut area and when it is used for duplicating a cast ${ }^{(6,7)}$.

The ear face-bow was used, as the arbitrary axis location is easier and a smaller amount of time consuming and it was found that the arbitrary posterior references were precise within $5 \mathrm{~mm}$ of the kinematic hinge axis for $95 \%$ of patients with ordinary jaw relationship ${ }^{(8-10)}$.

Semi-adjustable articulator tries to simulate patient's condylar path by mechanical equivalents which are able of reproducing all or part of its move. This articulator is normally used where some degree of precision work is mandatory. It does not demand an inordinate amount of time or expertise as when using fully adjustable articulator. Casts mounted on this articulator induce about the same spatial dimension as the condyle to the teeth, so discrepancies in the difference in the radius of arc of closure is reduced. This has a considerable clinical significance as occlusal corrections in the finished restoration are $\operatorname{minimize}^{(11,12)}$.

The thickness of impression compound material used for centric, protrusive, interocclusal records were kept $3 \mathrm{~mm}$ for clinical and to eliminate the influence of the changes in the vertical dimension and the anteroposterior reposition of the mandible, impression compound material was used because of its rigidity so it could resist distortion during its insertion and removal ${ }^{(13)}$.

Construction of a single denture with single denture base for all examined occlusal schemes not a duplicate denture was recommended to avoid dimensional changes in denture materials so produce similar dentures not identical and also to decrease expenses and time consumed ${ }^{(14)}$

Also alterations in occlusal surfaces are irreversible and permanent. Teeth assemblies procedures may be repetitive to make any number of alternate posterior teeth assemblies as wanted and they will all function on the original maxillary and mandibular denture bases with the same unique jaw relationship and vertical dimensions of occlusion. Because all the assemblies can be connected, removed and reconnected to the unchanged denture base ${ }^{(15)}$.

Balance is now believed necessary during several excursive movements such as swallowing saliva, closing to reseat dentures, and bruxism performed by patients in between meals. Therefore, if the balance is not existing, the bases could shift, tip or torque on their foundations during the eccentric movements and cause inflammation leading to accelerated bone resorption. Though several authors claim these contacts other than mastication are not probably to be made with any great deal of force, it is seen many patients appreciate comfort only when the eccentric balance is present. Equal contact of all posterior teeth (centric occlusion) in centric relation is essential for the health of the mucosa ${ }^{(16)}$.

Setting anatomical or semi-anatomical posterior teeth is to generate balancing occlusion and assure that all posterior teeth as well as anterior teeth maintain in contact during lateral excursions, to ensure bilateral balanced occlusion an antro-posterior curve is placed in the arch which is Compensating curve and it's analogous to the curve of Spee in ordinary dentition and another curve from side to side which is curve of Wilson. Processing errors are an inevitable part and hence for patient's comfort, Laboratory remounting is imperative step need to be followed after processing of each and every complete denture ${ }^{(17)}$.

Clinical remounting is essential because it is difficult to see occlusal discrepancies intraorally with complete dentures. The resiliency of the supporting tissues and the displaceability of the tissues in varying degrees tend to handle premature occlusal contacts. The tissues permit the dentures to shift; as a result, after the first interceptive occlusal contact the remaining teeth appear to reach satisfactory contacts ${ }^{(18)}$. 
Selective grinding was made to spot minimal occlusal interference intraorally and it is considered the most common and more used way for modifying occlusal discrepancies ${ }^{(19)}$.

Masseter and temporalis muscles were selected for demonstrating the masticatory muscle activity since they are the largest and strongest masticatory muscles, in addition to their ease of access during recording. The anterior temporalis muscles were chosen because, as spindle-rich jaw closers, they present one direction by which neuromuscular processes ensure that appropriate forces are brought to bear on food particles. Records were made for the masseter and temporalis muscles bilaterally to avoid difference in the activity of the recorded muscle as a consequence of variations in the preferable chewing side for patient ${ }^{(20)}$.

Electromyography "EMG" is a specific technique used to measure the activity of specific muscles. It is widely used in experimental analyses of the masticatory system; surface electromyography has provided the ways to further our accepting of the physiology of the masticatory system ${ }^{(21)}$.

In this study two unlike types of food was used one representative soft food "banana" and "carrots" as hard one. Kapur proposed an evaluation of various test foods used for evaluating masticatory efficiency in denture wearers, the fibrous ones such as lettuce and celery, while hard ones such as chestnuts and sausages were among the easiest ones. Moreover, it was detected that raw carrot was the most resistant foods, presenting a high accuracy in reliability tests, and thus a good candidate for subsequent studies ${ }^{(22-24)}$.

Studies revealed two measurements which were recorded during chewing the food specimens, these are: numbers of chewing strokes up mouth was free of foods and time (in seconds) until the mouth was clear of food ${ }^{(25)}$.

\section{CONCLUSION}

1- Improvement in masticatory efficiency and lowering in electromyographic activity in patients using bilateral balanced occlusion obtained through clinical remounting with flexible denture

2- No significant differences were found in masticatory efficiency and electromyographic activity between the three types of remounting during chewing soft food for both conventional denture base and flexible denture base during chewing soft food.

\section{REFERENCES}

1. Olvera N, Jones JD. Alternatives to traditional complete dentures. Dent Clin North Am. 2014; 58:91-102.

2. Kamal S, Chandrasekharan N. Problem solving in complete dentures-An overview. ResearchGate.2014.

3. Prasad K, Prasad B, Bardia A, Prasad A. Enhancing stability; a review of various occlusal schemes in complete denture prosthesis. J Health Sci. 2013; 3: 105-11.

4. Iwasaki LR, Gonzalez YM, Liu H, Marx DB, Gallo LM, Nickel JC. A pilot study of ambulatory masticatory muscle activities in temporomandibular joint disorders diagnostic groups. Orthod craniofac res. 2015; 18:146-55.

5. Shah J, Bulbule N. Comparative Evaluation of Sorption, Solubility and Microhardness of heat cure polymethyl methacrylate denture base resins and flexible denture base material. J Clin Diagn Res. 2014; 8:1-4.

6. Gowri N, Gopichander N, Solomon E. The Facar Concept. Int J Dent Sci. 2008; 7: 1-6.

7. Lavanya AS, Azhagarasan NS, Shetra S. Comparative study of the effect of three different interocclusal recording materials or reproducibility of horizontal condylar registrations in two different semiadjustable articulators: A clinical study. Int J Prosthodont and Rest Dent. 2011; 1: $155-62$.

8. Daniela F, Figueira N, Renata BLP, Leonardo M. Doubleblind study for evaluation of complete dentures made by two techniques with and without face-bow. Braz J Oral Sci. 2004; 3:439-45.

9. Ozkurt Z, Kazazoglu E. Treatment modalities of single-tooth missing in a Turkish subpopulation: implant, fixed partial denture, or no restoration. J Dent Sci. 2010; 5:183-8. 
10. Alvarez MC, Turbino ML, Barros C, Pagnano VO, Bezzon OL. Comparative study of intermaxillary relationships of manual and swallowing methods. Braz Dent J. 2009; 20:78-83.

11. Lang LA, Holmes DC, Passon C, Trombly RM, Astroth JD, Tavel AF. Introducing dental students to clinical patient care: the complete denture prosthodontics transition clinic. J Prosthodont 2003;12:206-10

12. Gianluca MT, Marco AM, Stefano B, Chiarella S. Masticatory muscle activity during maximum voluntary clench in different research diagnostic criteria for temporomandibular disorders (RDC/TMD) groups. Manual Therapy. 2007; 1-7.

13. Himkat A. Comparision of sectional border using different molding and final impression materials on retention of maxillary complete dentures. IOSR J Dent Med Sci 2015; 14:35-40.Prince K, Ashish K, Roshni G, Ashish K. Anterior point of reference: Current knowledge and perspectives in prosthodontics. J Orofacial Sci. 2012; 4:96-9.

14. Choi BH, Jeong SM, Lee CU, An XY, Fang JH, Oh JH. An accuracy assessment of virtual bite registration in edentulous patients. Clin Oral Impl Res. 2017; 28:183.

15. Pregl V, Pošti SD. Influence of balanced occlusion in complete dentures on the decrease in the reduction of an edentulous ridge. J Prosthet Dent. 2012; 69:155-60.

16. Koc D, Dogan A, Bek B. Effect of gender, facial dimensions, body mass index and type of functional occlusion on bite force. J Appl Oral Sci 2011; 19: 274-9.
17. Jafar G, Nafiseh A, Foad S, Maryam G. Dimensional changes of acrylic resin denture bases: conventional versus injection-molding technique. J Dent Tehran.2014; 11:398405.

18. Mansi P, Ponnanna AA, Gaurav T. Guiding Intellect for Occlusal Errors. J Clin Diagn Res. 2013; 7: 2619-22.

19. Shikha N, Himanshu S, Pankaj G. Complete-denture insertion appointment:what to look for?. Int J Enhanced Research in Medicines \& Dental Care.2014; 1: 4-13.

20. Mamta DC, Shankar PD, Arun NK, Smita PV. A simplified chair-side remount technique using customized mounting platforms. J Adv Prosthodont. 2012; 4:170-3.

21. Castroflorio T, Bracco P, Farina D. Surface electromyography in the assessment of jaw elevator muscles. J Oral Rehabil. 2008; 35: 638-45.

22. Goiato MC, Garcia AR, dos Santos DM. Electromyographic activity of the mandible muscles at the beginning and end of masticatory cycles in patients with complete dentures. Gerontology. 2008; 54:138- 43.

23. Gonzalez Y, Iwasaki LR, McCall Jr WD, Ohrbach R, Lozier E, Nickel JC. Reliability of electromyographic activity vs. bite-force from human masticatory muscles. Eur J Oral Sci 2011; 119: 219- 24.

24. Abd El Aziz O, Saba EKA, Mesallati SA. Masticatory efficiency of complete dentures constructed by different denture base materials. Int J Sci and Research. 2016; 5:1292-9. 